20.9 percent for strontium ranelate - are given both in the Results section and in Figure 2.

Pierre J. Meunier, M.D.

Edouard Herriott Hospital

69437 Lyon, France

pierre.meunier@laennec.univ-lyonl.fr

1. D'Haese PC, Verberckmoes SC, Schrooten I, De Broe ME. Strontium and chronic renal failure. Kidney 2000;9:93-8.

2. Spasovski GB, Bervoets AR, Behets GJ, et al. Spectrum of renal

bone disease in end-stage renal failure patients not yet on dialysis.

Nephrol Dial Transplant 2003;18:1159-66.
3. Cohen-Solal ME, Augry F, Mauras Y, Morieux C, Allain P, de Vernejoul MC. Fluoride and strontium accumulation in bone does not correlate with osteoid tissue in dialysis patients. Nephrol Dial Transplant 2002;17:449-54.

4. D'Haese PC, Couttenye MM, Lamberts LV, et al. Aluminum, iron, lead, cadmium, copper, zinc, chromium, magnesium, strontium, and calcium content in bone of end-stage renal failure patients. Clin Chem 1999;45:1548-56.

5. Vanholder R, Cornelis R, Dhondt A, Lameire N. The role of trace elements in uraemic toxicity. Nephrol Dial Transplant 2002; 17:Suppl 2:2-8

\title{
Circulating Angiogenic Factors and Preeclampsia
}

TO THE EDITOR: Levine et al. (Feb. 12 issue) ${ }^{1}$ have shown that increased levels of soluble fms-like tyrosine 1 (sFlt-1) and reduced levels of placental growth factor (PIGF) predict the development of preeclampsia, a few weeks before the onset of clinical symptoms. Circulating angiogenic factors produced by the placenta could therefore be used to predict preeclampsia. Since vascular endothelial growth factor (VEGF) levels did not differ significantly between the controls and the women who later had preeclampsia, attention has been focused on PIGF and sFlt-1 modifications. However, differences in free VEGF concentrations might have been underestimated because measurements were performed in serum samples, not in plasma samples. ${ }^{2}$ Serum samples do not reflect the placental production of VEGF, since they are "contaminated" by the release of VEGF from platelets and other blood cells during clotting, and it has been recommended that free VEGF be measured in plasma samples. ${ }^{3}$ We agree that prospective longitudinal studies are needed to assess the relevance of these markers (sFlt- 1 and PIGF) for the prediction of preeclampsia. Such studies should also include VEGF measurements in maternal plasma.

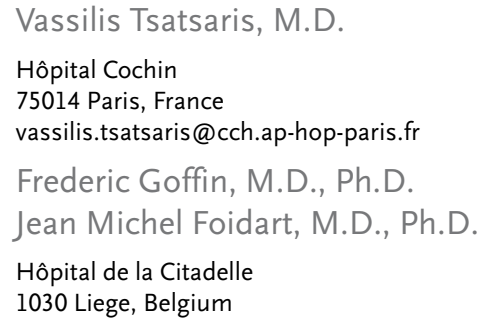

1. Levine RJ, Maynard SE, Qian C, et al. Circulating angiogenic factors and the risk of preeclampsia. N Engl J Med 2004;350:672-83.

2. Tsatsaris V, Goffin F, Munaut C, et al. Overexpression of the soluble vascular endothelial growth factor receptor in preeclamptic patients: pathophysiological consequences. J Clin Endocrinol Metab 2003;88:5555-63.
3. Jelkmann W. Pitfalls in the measurement of circulating vascular endothelial growth factor. Clin Chem 2001;47:617-23.

THE AUthors REPLY:We thank Dr. Tsatsaris and colleagues for pointing out that low free VEGF concentrations may have the potential to predict preeclampsia. We agree that measurements in serum, rather than plasma, may have reduced our ability to discriminate between women who subsequently had preeclampsia and those who did not. Perhaps even more important is the fact that the minimal detectable VEGF concentration with the immunoassay we used (R\&D Systems) was about 5 pg per milliliter - not much lower than the mean serum concentration during clinical preeclampsia in the women in our study (6.4 pg per milliliter). It is likely that plasma VEGF concentrations are even lower, since the contribution from platelets is not included. In fact, Tsatsaris et al. ${ }^{1}$ reported that in their study, free VEGF was not detectable in most maternal plasma specimens, and we have been unable to detect free VEGF in fresh plasma obtained during preeclampsia (unpublished data). Regardless of whether plasma or serum is used, an assay must have a sensitivity of $1 \mathrm{pg}$ or less of free VEGF per milliliter to be clinically useful. Unless such an assay is developed, it will be impossible to determine whether measurements of VEGF in plasma may be better than serum measurements for the prediction of preeclampsia.

Richard J. Levine, M.D., M.P.H.

National Institute of Child Health and Human Development Bethesda, MD 20892

levinerj@mail.nih.gov

\section{S. Ananth Karumanchi, M.D.}

Beth Israel Deaconess Medical Center

Boston, MA 02215

sananth@bidmc.harvard.edu 
1. Tsatsaris V, Goffin F, Munaut C, et al. Overexpression of the soluble vascular endothelial growth factor receptor in preeclamptic pa-

tients: pathophysiological consequences. J Clin Endocrinol Metab 2003;88:5555-63.

\section{Risks of Testosterone Replacement}

TO THE EDITOR: Rhoden and Morgentaler ${ }^{1}$ and Snyder $^{2}$ (Jan. 29 issue) assuage the anxiety of physicians who administer testosterone to older men because the men report andropause, a collection of ill-defined maladies related to male aging. Their position in this regard is very disconcerting.

More than 50 years ago, physicians began treating the "male climacteric" with testosterone. ${ }^{3}$ Since then, no standardized definition of this condition has been developed, no metric defining a therapeutic effect has been created, no randomized controlled studies have been conducted to support the widespread use of testosterone in men for this condition, and the adverse-event profile of the drug in this population has not been studied adequately. The Food and Drug Administration (FDA) has not approved testosterone for this condition. In addition, the schemes suggested by Rhoden and Morgentaler and by Snyder for managing the risk of prostate cancer, a hazard of testosterone exposure that is of great concern, are untested.

The Women's Health Initiative advanced our understanding of the risks and benefits of estrogen through randomized trials. The recent Institute of Medicine report ${ }^{4}$ advises thoughtful, well-designed research on testosterone in aging men; this should be supported.

Daniel A. Shames, M.D

Food and Drug Administration Rockville, MD 20857

1. Rhoden EL, Morgentaler A. Risks of testosterone-replacement therapy and recommendations for monitoring. N Engl J Med 2004 350:482-92.

2. Snyder PJ. Hypogonadism in elderly men - what to do until the evidence comes. N Engl J Med 2004;350:440-2.

3. Rothman SM, Rothman DJ. The pursuit of perfection: the promise and perils of medical enhancement. New York: Pantheon Books, 2003:158.

4. Liverman CT, Blazer DG, eds. Testosterone and aging, clinical research directions. Washington, D.C.: National Academies Press, 2004.

TO THE EDITOR: We wish to address several points made by Rhoden and Morgentaler and by Snyder, as highlighted by a recent case. A 59-year-old man with idiopathic hypogonadism who was receiving testosterone-replacement therapy was referred because of a rising prostate-specific antigen (PSA) level (4.0 ng per milliliter; total testosterone level, 202 ng per deciliter; free testosterone level, 45 pg per milliliter). Biopsy revealed adenocarcinoma of the prostate (Gleason grade, 6). A radical retropubic prostatectomy was performed. Pathological examination revealed extensive organ-confined adenocarcinoma (Gleason grade, 6; tumor-nodemetastasis stage, T2NOMx). Three and six months postoperatively, PSA was undetectable, and without testosterone replacement, his testosterone levels were 410 and 487 ng per deciliter, respectively.

Because prostate cancer can suppress the hypothalamic-pituitary-testicular axis and lower serum testosterone levels, ${ }^{1,2}$ we propose that adenocarcinoma of the prostate be considered in the differential diagnosis of hypogonadism. Furthermore, because removal of the prostate may lead to normalization of testosterone levels in hypogonadal men who have previously received testosteronereplacement therapy, we recommend measurement of testosterone before therapy is reinstated after surgery.

Edward M. Schaeffer, M.D., Ph.D. Patrick C. Walsh, M.D.

Johns Hopkins Medical Institutions Baltimore, MD 21287-2101

1. Miller LR, Partin AW, Chan DW, et al. Influence of radical prostatectomy on serum hormone levels. J Urol 1998;160:449-53.

2. Madersbacher S, Schatzl G, Bieglmayer C, et al. Impact of radical prostatectomy and TURP on the hypothalamic-pituitary-gonadal hormone axis. Urology 2002;60:869-74.

TO THE EDITOR: In reviewing the risks of testosterone replacement in older men, Rhoden and Morgentaler did not mention a safety concern specific to transdermal gels and creams: the transfer of testosterone from the patient to a partner or child through skin-to-skin contact. Reports from France describe women who had supraphysiologic testosterone levels, signs of hirsutism, or both after 